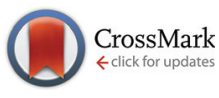

Cite this: Dalton Trans., 2015, 44 20826

Received 13th October 2015, Accepted 10th November 2015

DOI: $10.1039 / c 5 d t 04000 k$

www.rsc.org/dalton

\title{
Microwave assisted synthesis of a mono organoimido functionalized Anderson polyoxometalate $\uparrow$
}

\author{
C. Ritchie $\star^{\mathrm{a}}$ and G. Bryant ${ }^{\mathrm{b}}$
}

\begin{abstract}
The synthesis of an aliphatic organoimido functionalized polyoxometalate has been achieved through a microwave assisted reaction protocol in the absence of any activating reagents. Characterization of the pendant amine containing polyanion $\left[\mathrm{Mo}_{6} \mathrm{O}_{18} \mathrm{NC}\right.$ $\left.\left(\mathrm{OCH}_{2}\right)_{3} \mathrm{MnMo}_{6} \mathrm{O}_{18}\left(\mathrm{OCH}_{2}\right)_{3} \mathrm{CNH}_{2}\right]^{5-}$ (1) includes single crystal XRD, NMR, ESI-MS, IR and SAXS.
\end{abstract}

Polyoxometalates (POMs) are a class of molecular metal oxides that possess a great degree of structural and compositional versatility. ${ }^{1-4}$ The major structural components of POMs are primarily constructed from the condensation of early transition metal oxyanions with the metal in high oxidation states, although this is by no means exclusive. ${ }^{5-7}$ One striking feature of these molecules is their ability to incorporate almost any element within their skeletal frameworks as heteroatoms, thus enabling further derivatization of the molecular anions, including the grafting of organic ligands..$^{8-16}$ In recent times, the routine organic functionalization of polyanions such as the Anderson-Evans and Lindqvist structural types has attracted notable attention..$^{10,14,17-26}$ In 2002-2003, Gouzerh and Hasenknopf et al. reported the symmetrical functionalization of the $\left[\mathrm{H}_{x}\left(\mathrm{MO}_{6}\right) \mathrm{Mo}_{6} \mathrm{O}_{18}\right]^{n-}\left(\mathrm{M}=\mathrm{Mn}^{\mathrm{III}}, \mathrm{Fe}^{\mathrm{III}}, \mathrm{Ni}^{\mathrm{II}}\right.$ and $\left.\mathrm{Zn}^{\mathrm{II}}\right)$ heteropolymolybdates by a variety of ligands, and since then there have been numerous analogues prepared bearing ligands grafted using a selection of coupling methodologies. ${ }^{24,27-30}$ Particular emphasis has since been placed on the development of inorganic-organic hybrids constructed from the so called $\mathrm{Mn}$ Anderson polyanion $\left[\mathrm{MnMo}_{6} \mathrm{O}_{18}\left\{\left(\mathrm{OCH}_{2}\right)_{3} \mathrm{CNH}_{2}\right\}_{2}\right]^{3-}$. Expansion of these methodologies towards the synthesis and unambiguous characterization of asymmetrically functionalized polyoxometa-

\footnotetext{
${ }^{a}$ School of Chemistry, University of Melbourne, Parkville, Melbourne 3010, Australia. E-mail: critchie@unimelb.edu.au

${ }^{b}$ Centre for Molecular and Nanoscale Physics, School of Applied Sciences, RMIT University, Melbourne 3001, Australia

$\dagger$ Electronic supplementary information (ESI) available: Experimental procedures, synthetic details, IR, UV-Vis, ESI-MS, ${ }^{1} \mathrm{H}$ NMR, combustion analysis, X-ray scattering and X-ray crystallography with CIF files. CCDC 1418707. For ESI and crystallographic data in CIF or other electronic format see DOI: 10.1039/ c5dt04000k
}

lates has become a hot area of focus within the polyoxometalate community. In particular, the preparation of asymmetrically functionalized precursors, with reactive pendant functional groups is highly desirable. This goal has been achieved through functionalization of $\left[\mathrm{XMo}_{6} \mathrm{O}_{18}(\mathrm{~L} 1)(\mathrm{L} 2)\right]^{3-} \mathrm{X}=\mathrm{Cr}, \mathrm{Mn}$ and $\mathrm{Al}$ where the tripodal organic ligands (L1) and (L2) that decorate its surface can be varied. ${ }^{31-33}$ To date, the majority of asymmetrically functionalized POMs of this type have been reported by the group of Cronin, where the initial work relied heavily on fortuitous fractional crystallization due to inherent mixtures of products. ${ }^{34}$ Recently however, the groups of Cronin and Wei have developed strategies that address the problem of product mixtures. Cronin et al. tackled the issue through the use of reverse phase column chromatography which facilitated the separation of unreacted starting materials from mono- and di-functionalised moieties to great effect. This approach takes advantage of the ability to control the hydrophobicity of the polyanion using protecting group chemistry. ${ }^{35}$ Wei et al. have also developed an elegant method where the controlled protonation of the polyanion surface prior to any organomodification results in a change in the reactivity pattern of the cluster enabling singlesided functionalization yielding the $\chi$ isomers $\left[\left\{\mathrm{RC}\left(\mathrm{CH}_{2} \mathrm{O}\right)_{3}\right\}\right.$ $\left.\mathrm{CrMo}_{6} \mathrm{O}_{18}(\mathrm{OH})_{3}\right]^{3-} \cdot{ }^{36}$

Regarding functionalization of the lindqvist structural class, several examples have been isolated through a range of methods. ${ }^{25,37,38}$ Typically, these methods involve the use of some form of activating agent such as DCC for the preparation of organo-imido derivatives from organic amine precursors. Notably in 2010, Wei successfully prepared $\left[\mathrm{Mo}_{6} \mathrm{O}_{18} \mathrm{NC}\right.$ $\left.\left(\mathrm{OCH}_{2}\right)_{3} \mathrm{MnMo}_{6} \mathrm{O}_{18}\left(\mathrm{OCH}_{2}\right)_{3} \mathrm{CNMo}_{6} \mathrm{O}_{18}\right]^{7-}$ which was the first time a Mn-Anderson had been coupled to the hexamolybdate lindqvist polyanion. This was achieved through application of the established DCC coupling protocol. Subsequent reports include further derivatization of this molecular rod with aniline derivatives, again with the use of DCC which is required for the activation of the terminal oxo group of the polyoxomolybdate precursor. ${ }^{39,40}$

Herein, we report the preparation of an asymmetrically functionalized Mn-Anderson bearing a pendant hexamolybdate 


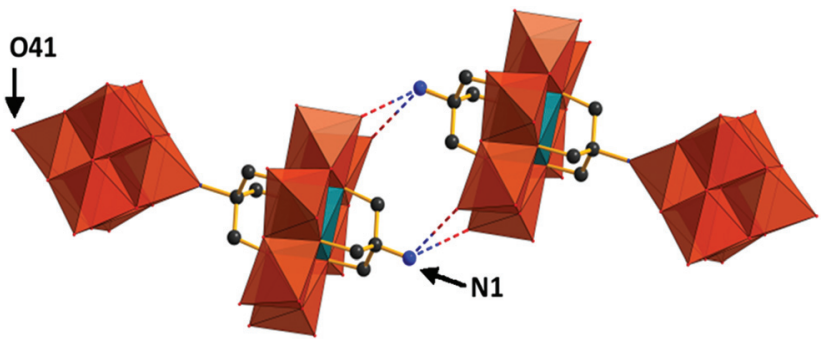

Fig. 1 Graphical representation of two molecules of (1) with solid state hydrogen bonding interactions displayed as broken bonds. Mo, orange; $\mathrm{Mn}$, teal; C, black; O, red; $\mathrm{N}$, blue.

polyanion and an additional terminal primary amine (Fig. 1). Remarkably, (1) was prepared in a one-pot process from a mixture of $\mathrm{TBA}_{4}\left[\mathrm{Mo}_{8} \mathrm{O}_{26}\right], \mathrm{Mn}(\mathrm{OAc})_{3} \cdot 2 \mathrm{H}_{2} \mathrm{O}$ and trishydroxymethylaminomethane in acetonitrile in the absence of any additional activating agents. Microwave irradiation of the stirred reaction mixture for 3 hours, at $110^{\circ} \mathrm{C}$ and 4 bar, results in the construction of the hybrid POM in modest yield (28\%). To the best of our knowledge, the in situ conversion of one polyanion precursor to two different structural classes, followed by their controlled coupling in a one pot process has never been previously reported. Despite this, it is no surprise that both $\mathrm{TBA}_{2}\left[\mathrm{Mo}_{6} \mathrm{O}_{19}\right]$ and $(\mathrm{TBA})_{3}\left[\mathrm{MnMo}_{6} \mathrm{O}_{18}\left(\mathrm{NH}_{2} \mathrm{C}-\right.\right.$ $\left.\left.\left(\mathrm{CH}_{2} \mathrm{O}\right)_{3}\right)_{2}\right]$ could be simultaneously prepared from this reaction mixture as $\mathrm{TBA}_{4}\left[\mathrm{Mo}_{8} \mathrm{O}_{26}\right]$ is the polyanion precursor of choice for the preparation of both these cluster types. Their coupling in a stoichiometric fashion through one organoimido linkage results in the unprecedented asymmetrically functionalized Mn-Anderson (1). Efforts to improve the reaction yield through the use of dry solvents had negligible effect, whereas increasing reagent concentrations results in a notable reduction in yield. The solubility of (1) in acetone, and the absence of any $\left[\mathrm{Mo}_{6} \mathrm{O}_{19}\right]^{2-}$ by-product, enabled the facile purification of the title compound due to the insolubility of the remaining products in this solvent. Recrystallization of the residual acetone insoluble material from acetonitrile, resulted in the isolation of predominantly unreacted (TBA) ${ }_{4}\left[\mathrm{Mo}_{8} \mathrm{O}_{26}\right]$, along with trace amounts of (TBA $)_{3}\left[\mathrm{MnMo}_{6} \mathrm{O}_{18}\left\{\left(\mathrm{OCH}_{2}\right)_{3}{ }^{-}\right.\right.$ $\left.\mathrm{CNH}_{2}\right\}_{2}$ ] and the previously reported di-functionalized organoimido species $(\mathrm{TBA})_{7}\left[\mathrm{Mo}_{6} \mathrm{O}_{18} \mathrm{NC}\left(\mathrm{OCH}_{2}\right)_{3} \mathrm{MnMo}_{6} \mathrm{O}_{18}\left(\mathrm{OCH}_{2}\right)_{3}\right.$ $\mathrm{CNMo}_{6} \mathrm{O}_{18}$ ].

Crystallographic analysis of (1) confirms the organoimido linkage between the two polyanions with the short $\mathrm{Mo} \equiv \mathrm{N}$ bonds (1.676-1.714 $\AA$ ) and nearly linear $\mathrm{Mo} \equiv \mathrm{N}-\mathrm{C}$ angle (175.5-178.5 ${ }^{\circ}$ being indicative of significant triple bond character. Shortening of the Mo-O bond (2.215 $\mathrm{A})$ trans to $\mathrm{Mo} \equiv \mathrm{N}$ vs. that typically observed in $\left[\mathrm{Mo}_{6} \mathrm{O}_{19}\right]^{2-}$, as well as the slight elongation of the equatorial $\mathrm{Mo}-\mathrm{O}$ bonds, is also indicative of the organoimido linkage. Inspection of the infrared spectroscopy (Fig. S1†) of (1) reveals the characteristic shoulder peak at $974 \mathrm{~cm}^{-1}$, which is diagnostic of monosubstituted organoimido derivatives of hexamolybdate. Furthermore, the IR spectra shows a shift of the $\mathrm{C}-\mathrm{O}$ stretch of the parent
Mn-Anderson from $1039 \mathrm{~cm}^{-1}$ to $1044 \mathrm{~cm}^{-1}$ with a significant shoulder at $1068 \mathrm{~cm}^{-1}$, indicating a strengthening of the $\mathrm{C}-\mathrm{O}$ bonds due to grafting of the hexamolybdate through the imido linkage. This is also observed in the crystallographic data, with a slight shortening of the $\mathrm{C}-\mathrm{O}$ bonds on the hexamolybdate functionalised side of the Mn-Anderson. Assignment of the ${ }^{1} \mathrm{H}$ NMR spectrum of (1) in [ $\mathrm{D}_{6}$-acetone], reveals the expected resonances for the TBA cations at 1.01, 1.50, 1.83 and $3.43 \mathrm{ppm}$. More problematic is the unambiguous assignment of the remaining $\mathrm{H}$ atoms found as part of the aliphatic $-\mathrm{C}\left(\mathrm{CH}_{2} \mathrm{O}\right)_{3}$ ligands as a result of the paramagnetic $\mathrm{Mn}^{\mathrm{III}}$ ion encapsulated in the Mn-Anderson. Nevertheless, two major broad resonances are observed at (62.50-63.75 ppm and 63.75$65.00 \mathrm{ppm}$ ) and are assigned to the methylene hydrogen atoms of $\mathrm{NH}_{2} \mathrm{C}\left(\mathrm{CH}_{2} \mathrm{O}\right)_{3}$ and $\mathrm{Mo} \equiv \mathrm{N}-\mathrm{C}\left(\mathrm{CH}_{2} \mathrm{O}\right)_{3}$ respectively. The observed downfield shift of the broad resonances when compared with the parent Mn-Anderson (61 ppm) is attributed to the strong electron withdrawing nature of the appended hexamolybdate. A trace amount, $(<2 \%)$ of $\left[\mathrm{MnMo}_{6} \mathrm{O}_{18}\left(\mathrm{NH}_{2} \mathrm{C}-\right.\right.$ $\left.\left.\left(\mathrm{CH}_{2} \mathrm{O}\right)_{3}\right)_{2}\right]^{3-}$ contamination is observed via ${ }^{1} \mathrm{H}$ NMR from the recrystallization of (1). The impurity is not due to decomposition of the title compound as confirmed by ${ }^{1} \mathrm{H}$ NMR experiments (Fig. S2 and S3†).

In order to probe the solution stability and therefore the potential applicability of (1) in the synthesis of more elaborate inorganic-organic hybrids, we undertook mass spectroscopy and small angle X-ray scattering experiments. The mass spectrum of an acetone solution of (1) reveals several well-defined isotopic envelopes that are assigned as the di- and tri-anionic forms of (1). Envelopes at 1251.14 and $1371.28 \mathrm{~m} / \mathrm{z}$ are readily assigned as the dianions $\mathrm{TBA}_{2} \mathrm{H}[1]^{2-}$ and $\mathrm{TBA}_{3}[1]^{2-}$, meanwhile the trianions $\mathrm{TBA}_{2}[1]^{3-}$ and $\mathrm{TBA}_{1} \mathrm{H}_{1}[1]^{3-}$ are observed at 834.42 and $753.33 \mathrm{~m} / \mathrm{z}$ (Fig. S4-S7†). Notably there is no evidence of any additional higher mass species indicating the absence of any higher nuclearity condensation products. This result along with the ease by which the sample can be recrystallized, enticed us to pursue the use of Small angle X-ray Scattering (SAXS) to probe the polyanion solution stability. The utilization of SAXS in the field of POMs is notably underdeveloped, however several key examples of its value have been reported..$^{8,41,42}$ The sensitivity of SAXS to the size and shape of species in solution make it a valuable technique to probe the integrity and stability of POMs, however, due to the inherently low information content, results must be interpreted in the light of additional information. Pure crystalline samples of $(\mathrm{TBA})_{3}\left[\mathrm{MnMo}_{6} \mathrm{O}_{18}\left(\mathrm{NH}_{2} \mathrm{C}\left(\mathrm{CH}_{2} \mathrm{O}\right)_{3}\right)_{2}\right]$ and $\mathrm{TBA}_{2}\left[\mathrm{Mo}_{6} \mathrm{O}_{19}\right]^{2-}$, were dissolved in acetonitrile and acetone respectively to conduct the control SAXS measurements. The measured radii of gyration for both controls, as well as the radii determined from fits assuming a spherical model, agree well with dimensions calculated from crystallographic data (Fig. S9 and S10 $†$ ). Analysis of scattering data acquired from an acetone solution of (1) (Fig. 2, top) results in an excellent fit with a cylindrical model, but a spherical model deviates at high scattering vector. As the cylindrical model has two parameters, different values of the radius and length over a small range can give similar fits, so 

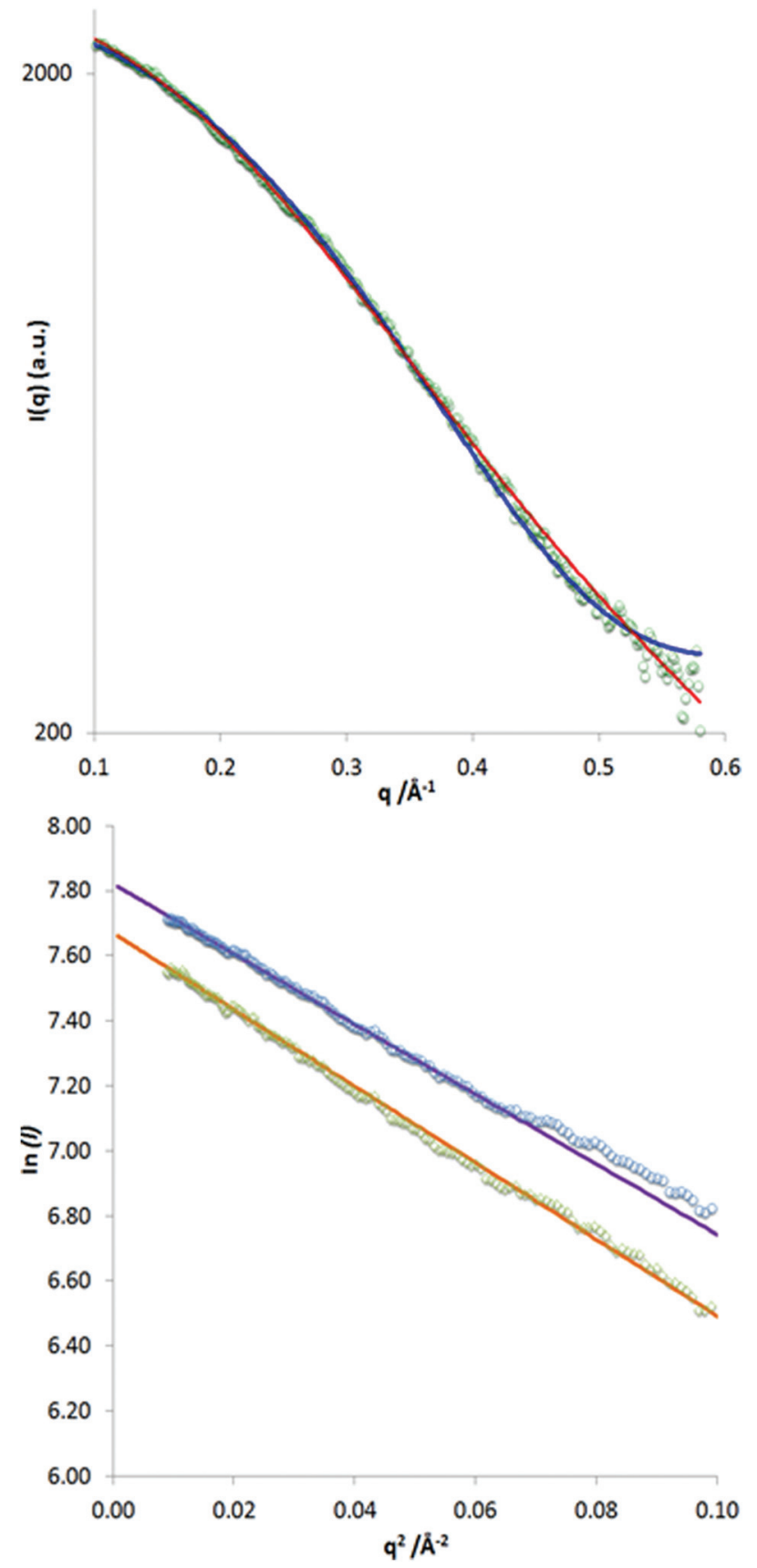

Fig. 2 SAXS data for a $3 \mathrm{mM}$ acetone solution of $\mathrm{TBA}_{5}\left[\mathrm{Mo}_{6} \mathrm{O}_{18} \mathrm{NC}\right.$ $\left(\mathrm{OCH}_{2}\right)_{3} \mathrm{MnMo}_{6} \mathrm{O}_{18}\left(\mathrm{OCH}_{2}\right)_{3} \mathrm{CNH}_{2}$ ] (top). Fits: cylindrical model (red), spherical model (blue). Guinier plots, whose low q linear fits yield the radius of gyration, for a fresh sample (purple), and a sample aged for 7 days (orange) (bottom).

we used calculated values based on the atomic coordinates from the single crystal X-ray diffraction studies to confirm the molecular shape and size. Crystallographically determined atom to atom separations from N2 to O41 (Fig. 1) yielded $L=$ 16.74 $\AA$, and an average radius of $R=4.19 \AA$ when considering the individual cross sections of the Anderson and Lindqvist components. Similarly a van der Waals calculation yielded $L=$
$18.28 \AA$ and $R=4.96 \AA$, with the averages of these values, $(L=$ $17.51 \AA$ and $R=4.58 \AA$ ) being used to fit the SAXS data of (1) with excellent agreement (Fig. 2, top). The stability of compound (1) in acetone over a period of 7 days was also confirmed by recollecting the SAXS data. Guinier analysis revealed a negligible change in the calculated radius of gyration (Fig. 2, bottom) with ${ }^{1} \mathrm{H}$ NMR also showing the retention of the characteristic NMR peaks at 62.50-63.75 ppm and 63.75-65.00 ppm on the aged sample (Fig. S3†).

In conclusion, we have demonstrated the viability and potential of microwave reaction conditions for the synthesis of novel POMs that are inaccessible using benchtop reaction conditions. The asymmetrically functionalised (1) was isolated in reasonable yield and excellent purity that has been confirmed by solid and solution state measurements. The solution stability of (1) has also been confirmed by spectroscopic and scattering techniques thus opening up avenues for its utility in the development of more elaborate inorganic-organic hybrids. Research focussed on the construction of functional photoactive and polymeric materials is currently underway and will be reported elsewhere in due course.

\section{Acknowledgements}

CR is a recipient of an Australian Research Council Discovery Early Career Researcher Award (project number DE130100615), and would like to acknowledge their financial support in addition to that provided by The University of Melbourne. This research was supported by the Australian Research Council grant LE120100186. The authors would also like to acknowledge the assistance of Dr Matthew Taylor and Ms Sioe See Volaric with the preparation and collection of the SAXS and MS data respectively.

\section{Notes and references}

1 X. López, J. J. Carbó, C. Bo and J. M. Poblet, Chem. Soc. Rev., 2012, 41, 7537-7571.

2 Y.-F. Song and R. Tsunashima, Chem. Soc. Rev., 2012, 41, 7384-7402.

3 J. J. Walsh, A. M. Bond, R. J. Forster and T. E. Keyes, Coord. Chem. Rev., 2016, 306, 217-234.

4 R. Yu, X. F. Kuang, X. Y. Wu, C. Z. Lu and J. P. Donahue, Coord. Chem. Rev., 2009, 253, 2872-2890.

5 M. T. Pope, Heteropoly and Isopoly Oxometalates, SpringerVerlag, Berlin, Heidelberg, 1st edn, 1983.

6 M. Nyman, Dalton Trans., 2011, 40, 8049-8058.

7 E. V. Chubarova, M. H. Dickman, B. Keita, L. Nadjo, F. Miserque, M. Mifsud, I. W. C. E. Arends and U. Kortz, Angew. Chem., Int. Ed., 2008, 47, 9542-9546.

8 M. Vonci, F. Akhlaghi Bagherjeri, P. D. Hall, R. W. Gable, A. Zavras, R. A. J. O'Hair, Y. Liu, J. Zhang, M. R. Field, M. B. Taylor, J. Du Plessis, G. Bryant, M. Riley, L. Sorace, 
P. A. Aparicio, X. López, J. M. Poblet, C. Ritchie and C. Boskovic, Chem. - Eur. J., 2014, 20, 14102-14111.

9 A. Macdonell, N. A. B. Johnson, A. J. Surman and L. Cronin, J. Am. Chem. Soc., 2015, 137, 5662-5665.

10 S. She, S. Bian, J. Hao, J. Zhang, J. Zhang and Y. Wei, Chem. - Eur. J., 2014, 20, 16987-16994.

11 P. Wu, P. Yin, J. Zhang, J. Hao, Z. Xiao and Y. Wei, Chem. Eur. J., 2011, 17, 12002-12005.

12 C. Yvon, A. J. Surman, M. Hutin, J. Alex, B. O. Smith, D. L. Long and L. Cronin, Angew. Chem., Int. Ed., 2014, 53, 3336-3341.

13 A. Proust, B. Matt, R. Villanneau, G. Guillemot, P. Gouzerh and G. Izzet, Chem. Soc. Rev., 2012, 41, 7605-7622.

14 V. Duffort, R. Thouvenot, C. Afonso, G. Izzet and A. Proust, Chem. Commun., 2009, 6062-6064.

15 A. Proust, R. Thouvenot and P. Gouzerh, Chem. Commun., 2008, 1837-1852.

16 B. Matt, S. Renaudineau, L.-M. Chamoreau, C. Afonso, G. Izzet and A. Proust, J. Org. Chem., 2011, 76, 3107-3112.

17 A. Bayaguud, J. Zhang, R. N. N. Khan, J. Hao and Y. Wei, Chem. Commun., 2014, 50, 13150-13152.

18 J. Zhang, J. Luo, P. Wang, B. Ding, Y. Huang, Z. Zhao, J. Zhang and Y. Wei, Inorg. Chem., 2015, 54, 2551-2559.

19 M. Hutin, C. Yvon, J. Yan, A. Macdonell, D.-L. Long and L. Cronin, CrystEngComm, 2013, 15, 4422-4430.

20 W. Clegg, R. J. Errington, K. A. Fraser, S. A. Holmes and A. Schäfer, J. Chem. Soc., Chem. Commun., 1995, 455.

21 R. N. Nasim Khan, N. Mahmood, C. Lv, G. Sima, J. Zhang, J. Hao, Y. Hou and Y. Wei, RSC Adv., 2014, 4, 7374.

22 G. Sima, Q. Li, Y. Zhu, C. Lv, R. N. N. Khan, J. Hao, J. Zhang and Y. Wei, Inorg. Chem., 2013, 52, 6551-6558.

23 Y.-F. Song, N. McMillan, D.-L. Long, J. Thiel, Y. Ding, H. Chen, N. Gadegaard and L. Cronin, Chemistry, 2008, 14, 2349-2354.

24 P. R. R. Marcoux, B. Hasenknopf, J. Vaissermann and P. Gouzerh, Eur. J. Inorg. Chem., 2003, 2003, 2406-2412.

25 T. R. Mohs, G. P. A. Yap, A. L. Rheingold and E. A. Maatta, Inorg. Chem., 1995, 34, 9-10.

26 Z. Jin, H. Jian, W. Yongge, X. Fengping, Y. Panchao and W. Longsheng, J. Am. Chem. Soc., 2010, 132(1), 14-15.
27 B. Hasenknopf, B. Hasenknopf, R. Delmont, R. Delmont, P. Herson, P. Herson, P. Gouzerh and P. Gouzerh, Eur. J. Inorg. Chem., 2002, 1081-1087.

28 U. Tong, W. Chen, C. Ritchie, X. Wang and Y. F. Song, Chem. - Eur. J., 2014, 20, 1500-1504.

29 A. Saad, O. Oms, J. Marrot, A. Dolbecq, K. Hakouk, H. El Bekkachi, S. Jobic, P. Deniard, R. Dessapt, D. Garrot, K. Boukheddaden, R. Liu, G. Zhang, B. Keita and P. Mialane, J. Mater. Chem. C, 2014, 2, 4748.

30 Y. F. Song, D. L. Long and L. Cronin, CrystEngComm, 2010, 12, 109-115.

31 M. H. Rosnes, C. Musumeci, C. P. Pradeep, J. S. Mathieson, D.-L. Long, Y.-F. Song, B. Pignataro, R. Cogdell and L. Cronin, J. Am. Chem. Soc., 2010, 132, 15490-15492.

32 O. Oms, K. Hakouk, R. Dessapt, P. Deniard, S. Jobic, A. Dolbecq, L. Nadjo, B. Keita, J. Marrot and P. Mialane, Chem. Commun., 2012, 12103-12105.

33 Y. Zhang, J. Huang, Y. Zhang and J. Wei, Priv. Commun., 2014.

34 Y. Song, D. Long, S. E. Kelly and L. Cronin, Inorg. Chem., 2008, 47, 9137-9139.

35 C. Yvon, A. Macdonell, S. Buchwald, A. J. Surman, N. Follet, J. Alex, D.-L. Long and L. Cronin, Chem. Sci., 2013, 4, 3810 .

36 J. Zhang, Z. Liu, Y. Huang, J. Zhang, J. Hao and Y. Wei, Chem. Commun., 2015, 51, 9097-9100.

37 Y. Du, A. L. Rheingold and E. A. Maatta, J. Am. Chem. Soc., 1992, 114, 345-346.

38 S. Gatard, S. Blanchard, B. Schollhorn, P. Gouzerh, A. Proust and K. Boubekeur, Chemistry, 2010, 16, 83908399.

39 J. Zhang, P. Yin, J. Hao, F. Xiao, L. Chen and Y. Wei, Chem. - Eur. J., 2012, 18, 13596-13599.

40 P. Wu, Q. Li, N. Ge, Y. Wei, Y. Wang, P. Wang and H. Guo, Eur. J. Inorg. Chem., 2004, 2004, 2819-2822.

41 P. Yin, T. Li, R. S. Forgan, C. Lydon, X. Zuo, Z. N. Zheng, B. Lee, D. Long, L. Cronin and T. Liu, J. Am. Chem. Soc., 2013, 135, 13425-13432.

42 O. Sadeghi, L. N. Zakharov and M. Nyman, Science, 2015, 347, 1359-1362. 